\title{
Design Performance of UWB Antenna for Portable Devices Applications
}

\author{
K. Madhu Sudhana Rao ${ }^{1 *}$ and M. V. S. Prasad ${ }^{2}$ \\ ${ }^{1}$ KKR and KSR Institute of Technology and Sciences, Guntur - 522017, Andhra Pradesh, India; \\ sudanrao65@gmail.com \\ 2RVR and JC College of Engineering, Chowdavaram, Guntur - 522019, Andhra Pradesh, India; \\ mvs_prasad67@yahoo.co.in
}

\begin{abstract}
Objectives: To review on the design of UWB antennas for the wireless applications and to propose suitable design. Methods/ Statistical Analysis: The study introduces a novel structure methods implementing the design are cutting multiple T-slots on a rectangular patch. The proposed structure occupied an area of $875 \mathrm{~mm}^{2}$ produces a reflection coefficient is $-44.58 \mathrm{~dB}$ and maintained $\mathrm{S}_{11} \leq-10 \mathrm{~dB}$ in the entire operating UWB region. The multiple T-slot antennas IBW's are 4.0-3.0 GHz $(1000$ MHz), 5.0-6.0 GHz (1000 MHz), 9.0-11.0 GHz (2000 MHz). Findings: The frequency considered from $3.1 \mathrm{GHz}-10.6 \mathrm{GHz}$ produces omnidirectional patterns of radiations with simple geometrical configuration. Proposed design produces higher performance compared to the narrow band systems. Produces a better return loss in the entire UWB region Application/ Improvements: The applications include the dielectric, planar, wearable antennas and paying specific attention to the areas of portable devices such as laptops, tablets, wearable computers, glasses and mobile phones etc.
\end{abstract}

Keywords: Impedance Bandwidth, Multiple T-Slots, Portable Devices, Reflection Coefficient, UWB Antenna

\section{Introduction}

The acceptance and definition released by FCC (Federal Communications Commission) for ultra wide band communication systems are inexpensive realizations which have become the key role topics in worldwide communication industry. However, UWB systems design becomes a challenging theme particularly for transmitting and receiving antennas. A UWB antenna are having advantages of a low manufacture cost, compactness, omnidirectional patterns of radiations in the operating bandwidth from 3.1-10.6 GHz. In ${ }^{1}$, impedance match wideband technique was proposed with an area of $1200 \mathrm{~mm}^{2}$ having a $S_{11}$ value is $-25 \mathrm{~dB}$ produced electrically compact active antenna. A wet performance bend UWB antenna is designed with area of $900 \mathrm{~mm}^{2}$ for application of textile industry produced reflection coefficient value is $-35 \mathrm{~dB}$ with range from 3.1-10.6 $\mathrm{GHz}^{2}$. Compact printed circuit board monopole ${ }^{3}$ antenna designed with an area of $950 \mathrm{~mm}^{2}$ produced $S_{11}$

*Author for correspondence value is $-32 \mathrm{~dB}$ in the operating band having VSWR is less than or equal to 2 . Square shape monopole antennas ${ }^{4}$ for UWB applications resonate at a frequency of $4.5 \mathrm{GHz}$ and $7.8 \mathrm{GHz}$ with reflection coefficient values are $-41 \mathrm{~dB}$ and $-35.5 \mathrm{~dB} . \mathrm{In}^{\frac{5}{5}} \tan$ shaped F-design is for monopole radiator having the reflection coefficient value is $-38 \mathrm{~dB}$ produced in the UWB system operating band from $2.3-10.5 \mathrm{GHz}$ maintained VSWR value is less than or equal to 2. By considering the dispersion ultra wide band antenna with an overall size is 1350 $\mathrm{mm}^{2}$ observed in ${ }^{-6}$ operated with a good return loss value is around $-43 \mathrm{~dB}$ in the applications of biomedical implantable and waveguide resonators. A monopole circular shape disc antenna is printed in ${ }^{7}$ with occupied antenna size $1600 \mathrm{~mm}^{2}$ produced a value of $S_{11}$ is $-41 \mathrm{~dB}$ with an operating band from $2.0-10.0 \mathrm{GHz}$. $\mathrm{In}^{8}$, a small compactness design antenna for UWB applications having a patch cutting at edges of the patch with rectangular slots and middle of the patch in a circular form of radius $3 \mathrm{~mm}$ produced a good return loss $-42 \mathrm{~dB}$ 
with IBW is $800 \mathrm{MHz}$. A tapered U shaped slot is cutting on the patch with a very small compactness in size is $960 \mathrm{~mm}^{2}$ produces a return loss is $-32 \mathrm{~dB}$ observed? Planar circular antenna having reconfigurable pattern ${ }^{10}$ designed with an area of $900 \mathrm{~mm}^{2}$ produced a $\mathrm{S}_{11}$ value is $-37 \mathrm{~dB}$ which maintained a VSWR value is 1.19 and entire band of UWB region is less than or equal to 2 . In the deigns $\frac{11-14}{2}$, the different UWB systems are designed with an over all sizes of the antenna are around 1000 $\mathrm{mm}^{2}$ to $1600 \mathrm{~mm}^{2}$ are observed the reflection coefficient are varying from $-25 \mathrm{~dB}$ to $-43 \mathrm{~dB}$ is observed.

Finally, a concise UWB antenna is designed for the applications of on-body in biomedical area having the size of the antenna is considered $60 \mathrm{~mm} \times 30 \mathrm{~mm}$ which produced a return loss is $-34 \mathrm{~dB}$. Table 1 shows the comparison of different antenna parameters with other existing systems. In the proposed system of multiple T-slots antenna proposed a very small compact design having an area $875 \mathrm{~mm}^{2}$ produced an efficiency around $89 \%$, VSWR value is 1.03 , impedance bandwidths are $1000 \mathrm{MHz}, 1000 \mathrm{MHz}$ and $2000 \mathrm{GHz}$ for the entire operating band range from $2.0-12.0 \mathrm{GHz}$.

Table 1. Comparison with existing methods

\begin{tabular}{|c|c|c|c|c|c|}
\hline $\begin{array}{c}\text { Published } \\
\text { Literature }\end{array}$ & $\begin{array}{c}\text { Total } \\
\text { occupied } \\
\text { size }\left(\mathbf{m m}^{2}\right)\end{array}$ & $\begin{array}{c}\text { Band- } \\
\text { width } \\
(\mathrm{GHz})\end{array}$ & $\begin{array}{c}\text { Return } \\
\text { loss } \\
(\mathrm{dB})\end{array}$ & VSWR & $\begin{array}{c}\text { Efficiency } \\
(\%)\end{array}$ \\
\hline$[2]$ & 900 & $2.0-8.0$ & -35 & 1.28 & 75 \\
\hline$[5]$ & 1225 & $3.1-10.6$ & -38 & 1.15 & 73 \\
\hline$[7]$ & 1600 & $2.0-10.0$ & -41 & 1.09 & 82 \\
\hline$[10]$ & 900 & $3.0-10.6$ & -37 & 1.19 & 81 \\
\hline$[12]$ & 880 & $3.0-10.6$ & -43 & 1.23 & 84 \\
\hline$[15]$ & 1800 & $2.0-8.5$ & -34 & 1.14 & 74 \\
\hline $\begin{array}{c}\text { Proposed } \\
\text { antenna }\end{array}$ & 875 & $2.0-10.0$ & -45 & 1.03 & 89 \\
\hline
\end{tabular}

Table 2. Geometrical values of proposed system

\section{Analysis and Antenna Design}

\subsection{Antenna Configuration}

The proposead structure consists of a dimensions $25 \mathrm{~mm}$ $\times 35 \mathrm{~mm}$ with an overall area of the system is $875 \mathrm{~mm}^{2}$. The design area of the patch is considered as $600 \mathrm{~mm}^{2}$. The material used to substrate is FR-4 (lossy) having relative permitivity of 4.3 , loss tangent is 0.025 and the patch substrate is Pefect Electric Conductor (PEC) with height of the antenna is considered as $1.6 \mathrm{~mm}$. In the entire patch four T-shaped slots are cutting on all the four edges of the patch in order to improve the return loss parameter of the proposed desgin. The micro strip line having a lenghth and width of the strips is taken as $5 \mathrm{~mm}$ and $3 \mathrm{~mm}$.

\subsection{Procedure to Antenna Design}

To investige antenna analysis design, the different satages of evaluation is shown in Figures 1 and 2. Initially, a basic patch antenna is designed with a compact dimensions of $30 \times 20 \mathrm{~mm}^{2}$ depicted in Figure 3 is antenna 1. It provides a single resonant frequency at $6.1 \mathrm{GHz}$ having the reflection coefficient $-42 \mathrm{~dB}$. Antenna 2 cutting the rectangular and square slots at the top and bottom patches to create a multiple slots in the patch to produced a return loss -30 $\mathrm{dB}$ and $-28 \mathrm{~dB}$ at two resonant bands at $2.5 \mathrm{GHz}$ and 9.1 GHz. To obtain the T-slots in the patch at the middle of the patch both on left and right sides of the patch taking a dimensions of $6 \mathrm{~mm}$ and $3 \mathrm{~mm}$ to create multiple T-slots resonate at $3.5 \mathrm{GHz}$ and $7.2 \mathrm{GHz}$ used in the applications of $\mathrm{Wi}-\mathrm{Fi}$ and $\mathrm{C}$-band produces a reflection coefficient values are $-32 \mathrm{~dB}$ and $-17 \mathrm{~dB}$ is observed in antenna 3 . Again to create sub T-multiple slots in the patch on all the four corners of the modifications with parametric analysis produced a return loss at $5.8 \mathrm{GHz}$ for WLAN application in antenna 4 . Finally, a paramrtris analysis take a parameter to design a UWB antenna four corners T-slots and middle of the patch on left and right create multiple T-slots is observed in antenna 5 produces three resonant band in UWB range of antenna.

\begin{tabular}{|l|c|c|c|c|c|c|c|c|c|c|c|c|c|c|}
\hline $\begin{array}{l}\text { Design } \\
\text { parameters }\end{array}$ & $\mathrm{L}$ & $\mathrm{W}$ & $\mathrm{L}_{\mathrm{p}}$ & $\mathrm{W}_{\mathrm{P}}$ & $\mathrm{A}$ & $\mathrm{B}$ & $\mathrm{C}$ & $\mathrm{D}$ & $\mathrm{E}$ & $\mathrm{F}$ & $\mathrm{G}$ & $\mathrm{H}$ & $\mathrm{I}$ & $\mathrm{J}$ \\
\hline Value $(\mathrm{mm})$ & 25 & 35 & 20 & 30 & 3 & 3 & 3 & 3 & 3 & 3 & 3 & 3 & 3 & 3 \\
\hline $\begin{array}{l}\text { Design } \\
\text { parameters }\end{array}$ & $\mathrm{K}$ & $\mathrm{L}$ & $\mathrm{L}_{\mathrm{p}}$ & $\mathrm{W}_{\mathrm{P}}$ & $\mathrm{L}_{1}$ & $\mathrm{~L}_{2}$ & $\mathrm{~L}_{3}$ & $\mathrm{~L}_{4}$ & $\mathrm{~L}_{5}$ & $\mathrm{~L}_{6}$ & $\mathrm{~W}_{1}$ & $\mathrm{~W}_{2}$ & $\mathrm{~W}_{3}$ & $\mathrm{~W}_{4}$ \\
\hline Value $(\mathrm{mm})$ & 3 & 3 & 5 & 3 & 4 & 9 & 9 & 9 & 4 & 4 & 6 & 6 & 4.5 & 20 \\
\hline
\end{tabular}




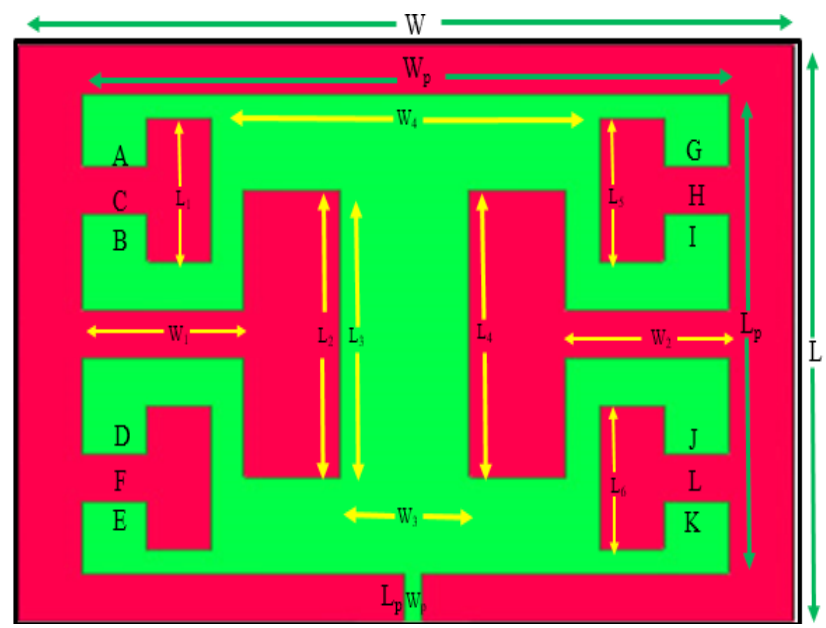

Figure 1. Geometry of multiple T-slots antenna.

\subsection{Surface Current Distributions}

To clarify the characteristics of radiation mechanism, the distribution of surface vectors of antenna 5 (final) at three resonant frequencies $3.7 \mathrm{GHz}, 5.8 \mathrm{GHz}$ and 10.25 $\mathrm{GHz}$ have been depicted in Figure 4. From Figure 4 (a) observes that the maximum current is flowing at the

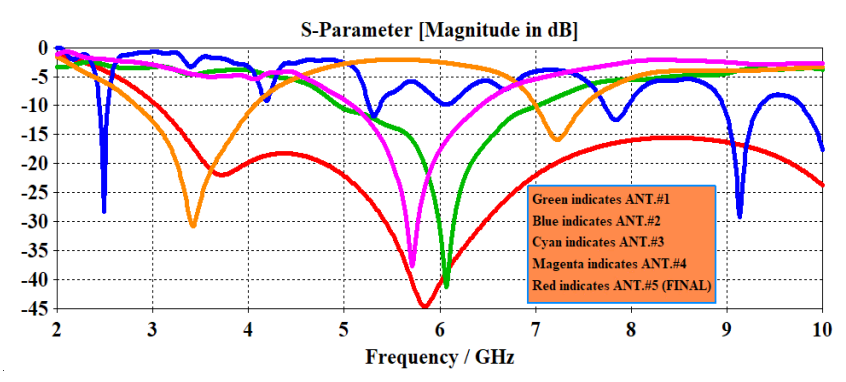

Figure 3. Evoutation stages S-parameters of multiple T-slots antenna.

middle of the patch in $y$-axis in the representation of parameter ' $\mathrm{L}$ ' with a length of $20 \mathrm{~mm}$ at this is resonate at $3.7 \mathrm{GHz}$. From Figure 4(b), it can be observed that maximum current flows in the direction of bottom of the patch in horizontal direction of left and right sides through the feeder location. This represents how the current is distributed in the antenna at bottom side observed at a frequency of $5.8 \mathrm{GHz}$. Finally, from Figure 4(c), the current is distributed equally almost at the horizontal and vertical axis at a frequency of 10.25 GHz.
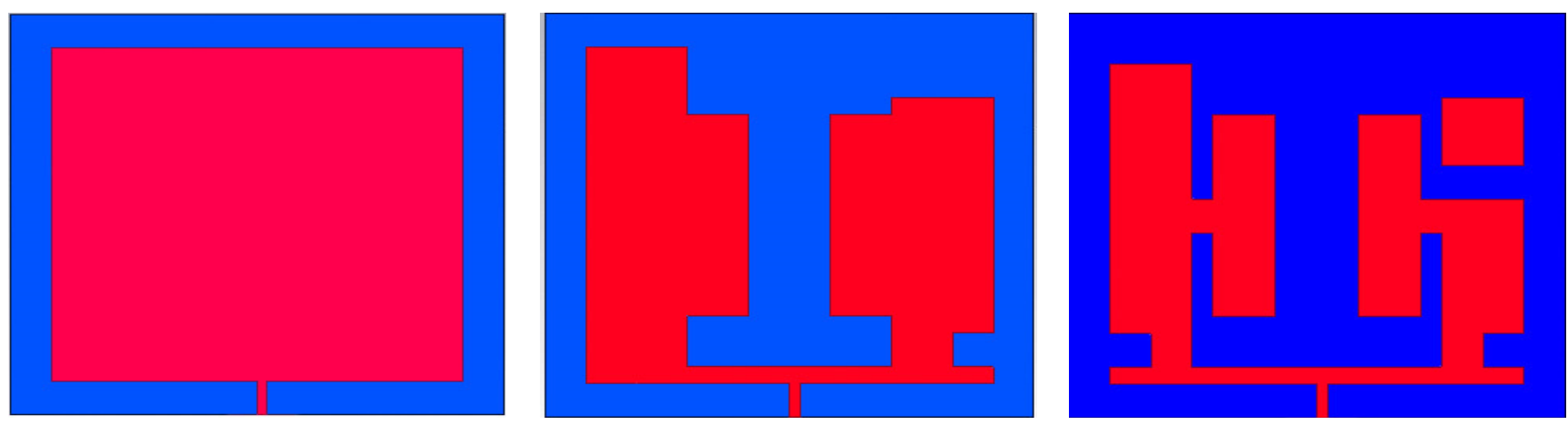

Stage \# 1 Stage \# 2 Stage \# 3

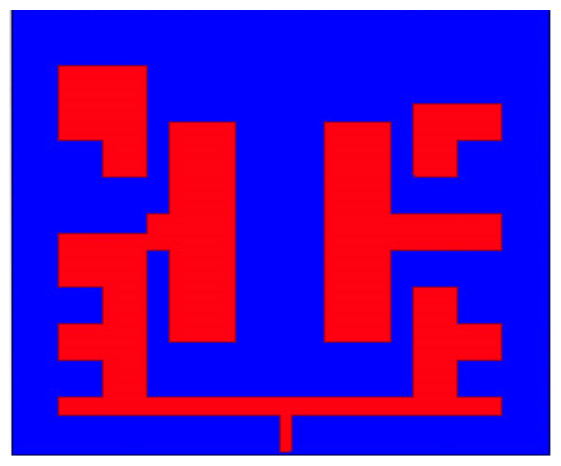

Stage \# 4

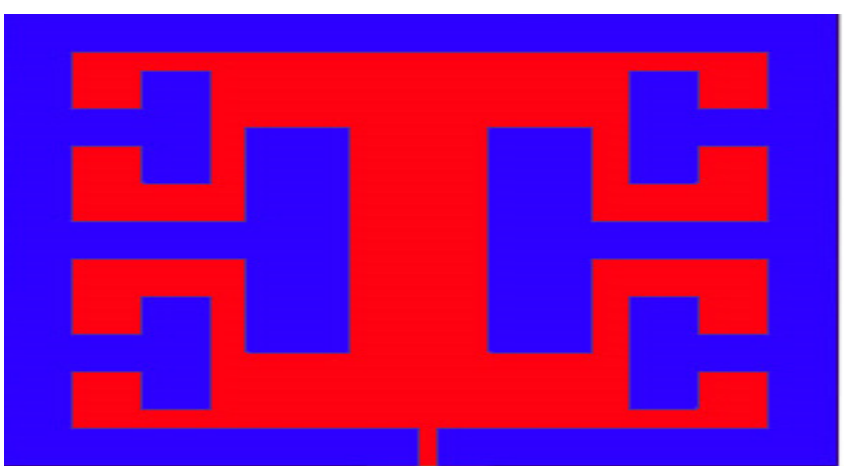

Stage \# 5 (final)

Figure 2. Step by step analysis of multiple T-slots antenna. 


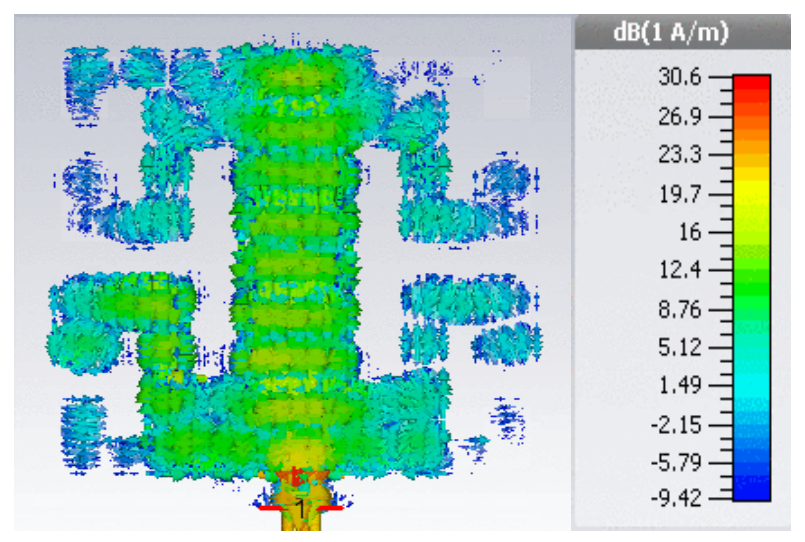

(a)

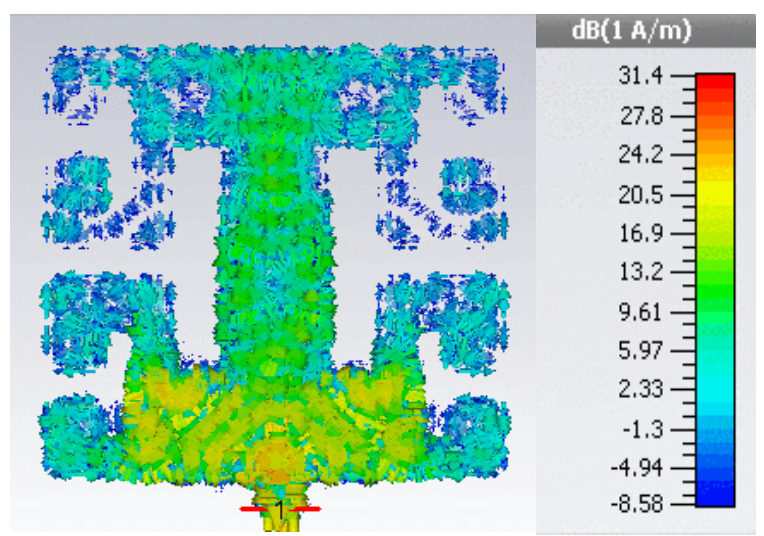

(b)

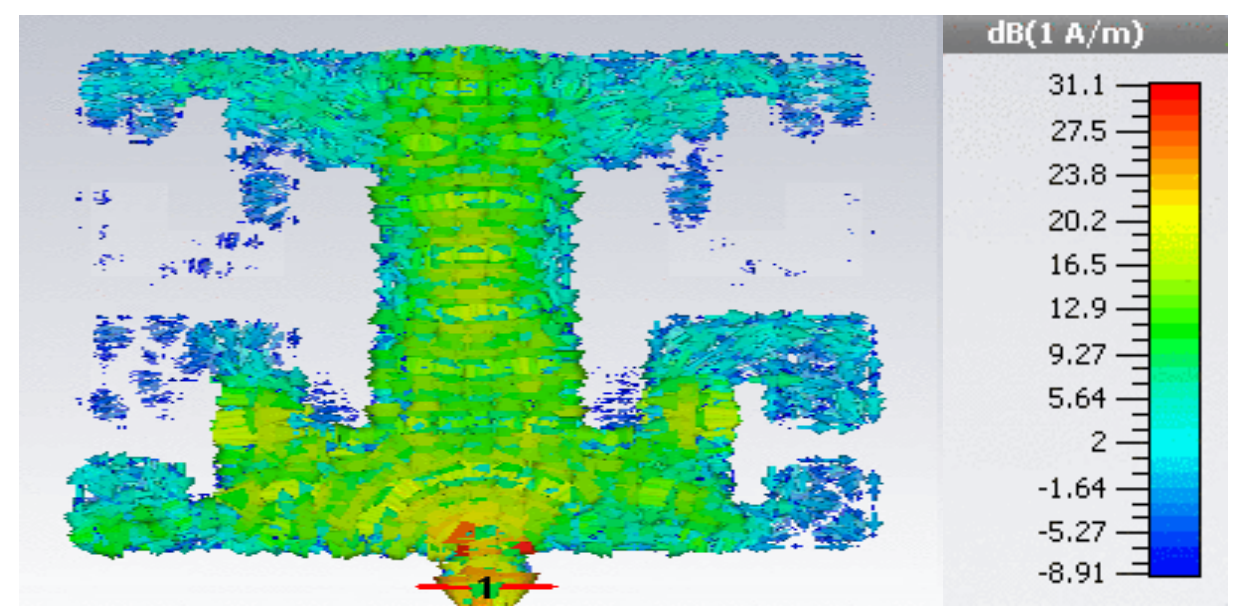

(c)

Figure 4. Surface current distribution of multiple T-slots antenna (a) $3.7 \mathrm{GHz}$ (b) $5.8 \mathrm{GHz}$ (c) $10.25 \mathrm{GHz}$.

\subsection{Parmatric Analysis}

In order to observe the effect of varying the different parameters in the proposed design to produce the return loss characteristics better in the UWB antenna design. Here, by varying the parameters on each T-slot on the radiating patch represent with different lengths $\mathrm{L}_{1}, \mathrm{~L}_{2}, \mathrm{~L}_{3}, \mathrm{~L}_{4}, \mathrm{~L}_{5}$ and $\mathrm{L}_{6}$, widths are $\mathrm{W}_{1}, \mathrm{~W}_{2}, \mathrm{~W}_{3}$ and $\mathrm{W}_{4}$. Applying parametric study analysis on lengths and widths on the patches for different values observe that the return losses are varying. It can be observed that five different cases varying the values of ' $L$ ' and ' $W$ ' is depicted in Figure 5. Consider the lengths $\mathrm{L}_{1}=3.5 \mathrm{~mm}$ and $\mathrm{W}_{1}=6.7 \mathrm{~mm}$, the antenna is resonate at three different frequencies $3.2 \mathrm{GHz}, 6.8 \mathrm{GHz}$ and $9.2 \mathrm{GHz}$ with all the resonate conditions $S_{11} \leq-10 \mathrm{~dB}$. In the second case, the lengths $\mathrm{L}_{1}=9.0 \mathrm{~mm}$ and $\mathrm{W}_{1}=10.0 \mathrm{~mm}$, the antenna is resonate at three different frequencies $4.0 \mathrm{GHz}$, 6.2 $\mathrm{GHz}$ and $10.2 \mathrm{GHz}$ with all the resonate conditions $\mathrm{S}_{11}$ $\leq-10 \mathrm{~dB}$. In the third case, the lengths $\mathrm{L}_{1}=4.5 \mathrm{~mm}$ and
$\mathrm{W}_{1}=5.8 \mathrm{~mm}$, the antenna is resonate at three different frequencies $3.8 \mathrm{GHz}, 5.8 \mathrm{GHz}$ and $10.24 \mathrm{GHz}$ with all the resonate conditions $S_{11} \leq-10 \mathrm{~dB}$. In the fourth case, the lengths $\mathrm{L}_{1}=7.0 \mathrm{~mm}$ and $\mathrm{W}_{1}=5.0 \mathrm{~mm}$, the antenna is resonate at three different frequencies $3.7 \mathrm{GHz}, 4.6 \mathrm{GHz}$ and $9.8 \mathrm{GHz}$ with all the resonate conditions $\mathrm{S}_{11} \leq-10 \mathrm{~dB}$. In the final case (proposed multi T-slot antenna), the lengths $\mathrm{L}_{1}=4.0 \mathrm{~mm}$ and $\mathrm{W}_{1}=6.0 \mathrm{~mm}$, the antenna is resonate at three different frequencies $3.7 \mathrm{GHz}, 5.8 \mathrm{GHz}$ and 10.25 $\mathrm{GHz}$ with all the resonate conditions $\mathrm{S}_{11} \leq-10 \mathrm{~dB}$. Similarly, by varying in other differnt cases the S-paramerters of the proposed system resonate at out of the UWB systems. In order to design an improvement in the pararametes like directive gain, efficiency of the antenna, VSWR, impedsnce bandwidth, IEEE gain of the analysis is observed the better results when designed the mutliple T-slot antenna taking a parametric study $\mathrm{L}_{1}=4.0 \mathrm{~mm}$ and $\mathrm{W}_{1}=6.0 \mathrm{~mm}$ is observed. 


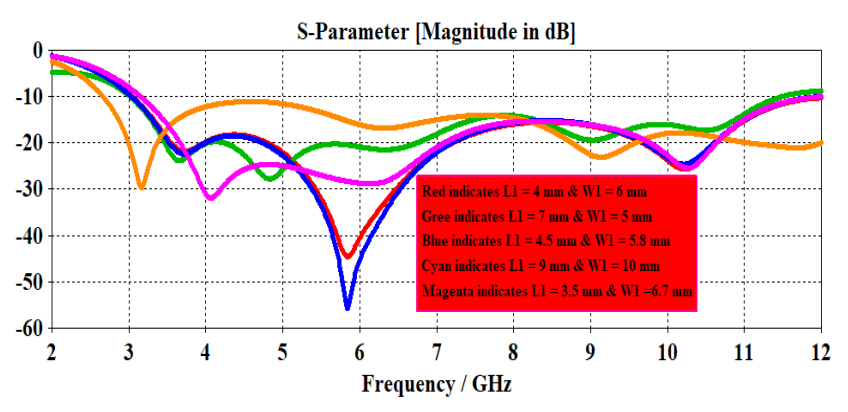

Figure 5. Parametric analysis of multiple T-slots antenna.

\section{Results and Discussion}

To validate the multiple T-slots, the proposed system simulated using CST Microwave Studio. Figure 6 shows the return loss of the proposed system in the range of UWB antenna. This results show that the antenna is resonate in the entire UWB system is $\mathrm{S}_{11} \leq-10 \mathrm{~dB}$ which produces a maximum value at the frequency of $5.8 \mathrm{GHz}$ around -45 $\mathrm{dB}$. The impedance bandwidths are observed at three resonant frequencies are $1000 \mathrm{MHz}, 1000 \mathrm{MHz}$ and $2000 \mathrm{MHz}$ in the entire UWB region. For the entire band of resonant frequencies in the UWB region the VSWR value is almost $\leq 2$ and which produces particularly at a maximum resonant frequency VSWR is 1.03 which is depicted in Figure 7.

The directivity of the proposed antenna system at the three resonant frequencies of $3.7 \mathrm{GHz}, 5.8 \mathrm{GHz}$ and 10.25 $\mathrm{GHz}$ are $3.3 \mathrm{dBi}, 2.1 \mathrm{dBi}, 5.8 \mathrm{dBi}$ is depicted in Figure 8. The radiation efficiencies of multiple T-slot antenna resonates at $3.7 \mathrm{GHz}, 5.8 \mathrm{GHz}$ and $10.25 \mathrm{GHz}$ are $90 \%$, $87 \%$ and $74 \%$. The radiation efficiency and total radiation efficiency of proposed system is simulated using CST MW studio, similarly this is also obtained by using the mathematical relation is the ratio pf radiation resistance to the loss resistance and radiation resistance is also got same approximately. The radiation efficiency of a multiple T-slot antenna system is depicted in Figure 9.

Figure 10 represents the multiple T-slot antenna radiation patterns in $\mathrm{xz}$-plane and yz-plane which indicates the both E-field and $\mathrm{H}$-field measurement. In the xz-plane the radiation pattern of E-plane is measured by considering theta is varying from $0^{\circ}$ to $360^{\circ}$ and phi is equal to zero and $\mathrm{H}$-field is measured similarly theta is varying from $0^{\circ}$ to $360^{\circ}$ and phi is equal $90^{\circ}$ is obtained in the yz-plane at the three resonant frequencies $3.7 \mathrm{GHz}, 5.8$ $\mathrm{GHz}$ and $10.25 \mathrm{GHz}$ is observed. From the Figure 10(a) the $\mathrm{xz}$-plane having the value is $-37 \mathrm{~dB}, \mathrm{yz}$-plane value is
$-150 \mathrm{~dB}$ at the resonate frequency of $3.7 \mathrm{GHz}$. From the Figure $10(\mathrm{~b})$ the $\mathrm{xz}$-plane having the value is $-122.7 \mathrm{~dB}$, $y z$-plane value is $-137 \mathrm{~dB}$ at the resonate frequency of 5.8 GHz. Similarly, From the Figure 10(c) the xz-plane having the value is $-10 \mathrm{~dB}$, yz-plane value is $-135 \mathrm{~dB}$ at the resonate frequency of $10.25 \mathrm{GHz}$ is observed.

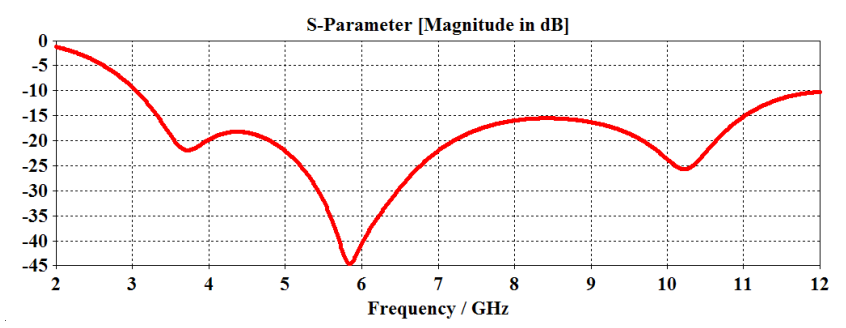

Figure 6. Reflection coefficient of multiple T-slots antenna.

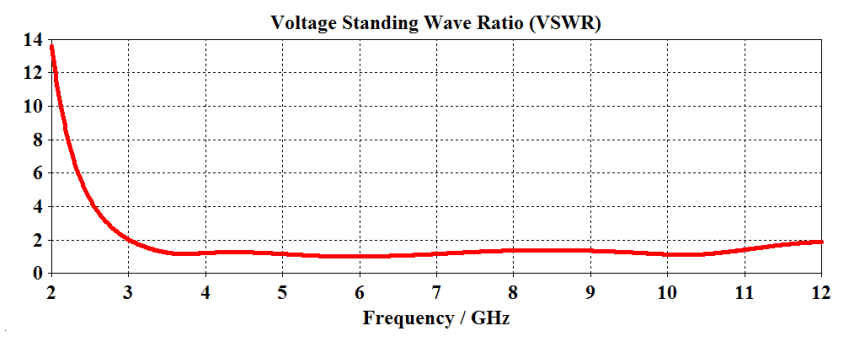

Figure 7. VSWR of multiple T-slots antenna.

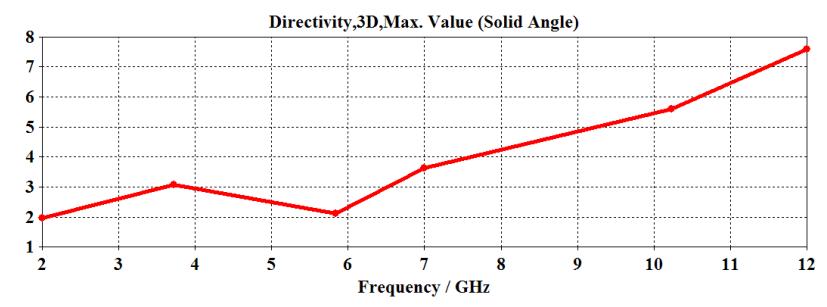

Figure 8. Directivity, 3D, maximum value of multiple T-slots antenna.

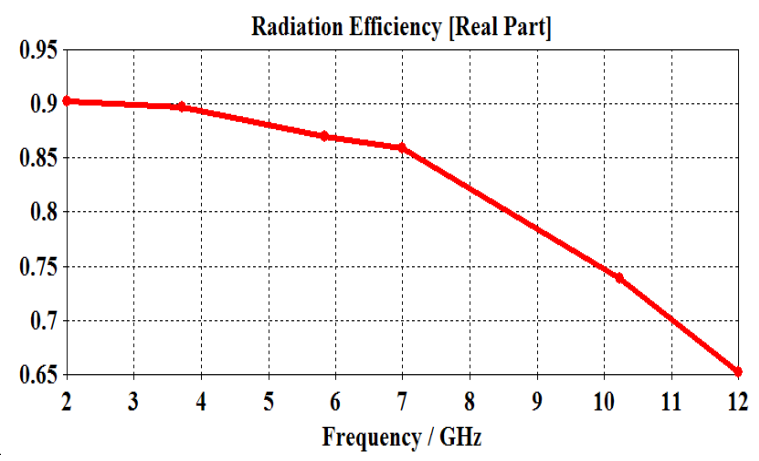

Figure 9. Radiation efficiency of multiple T-slots antenna. 

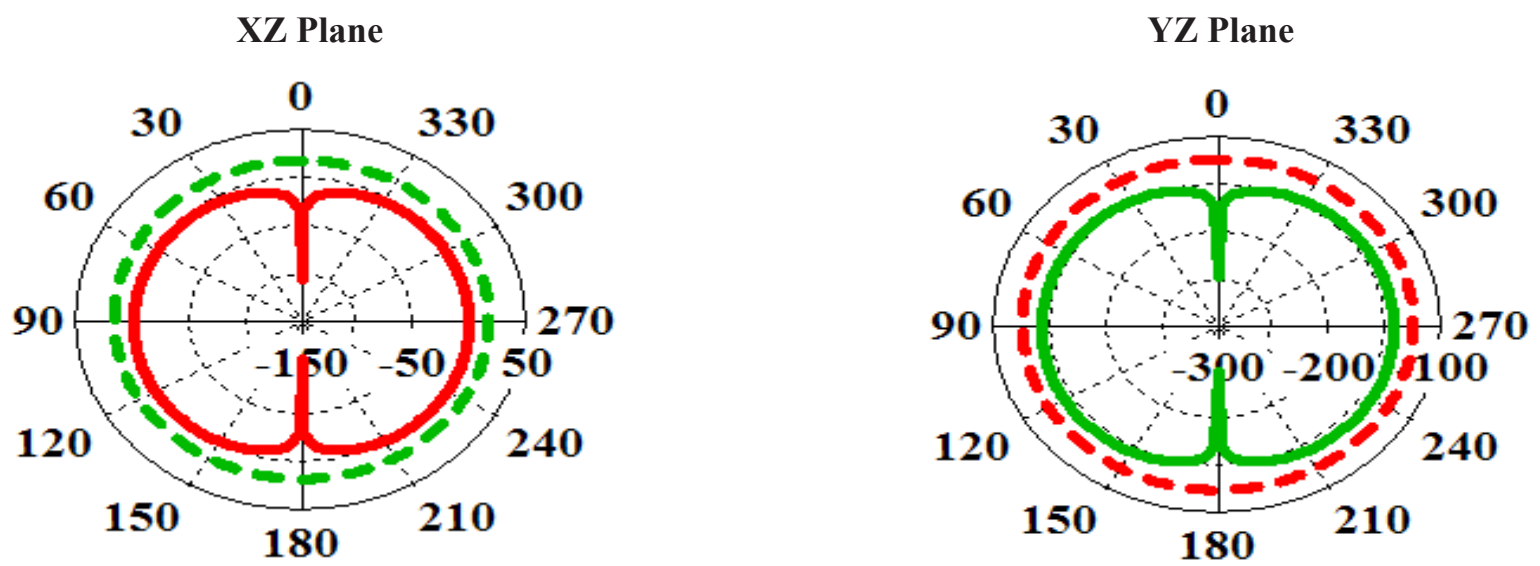

(a)
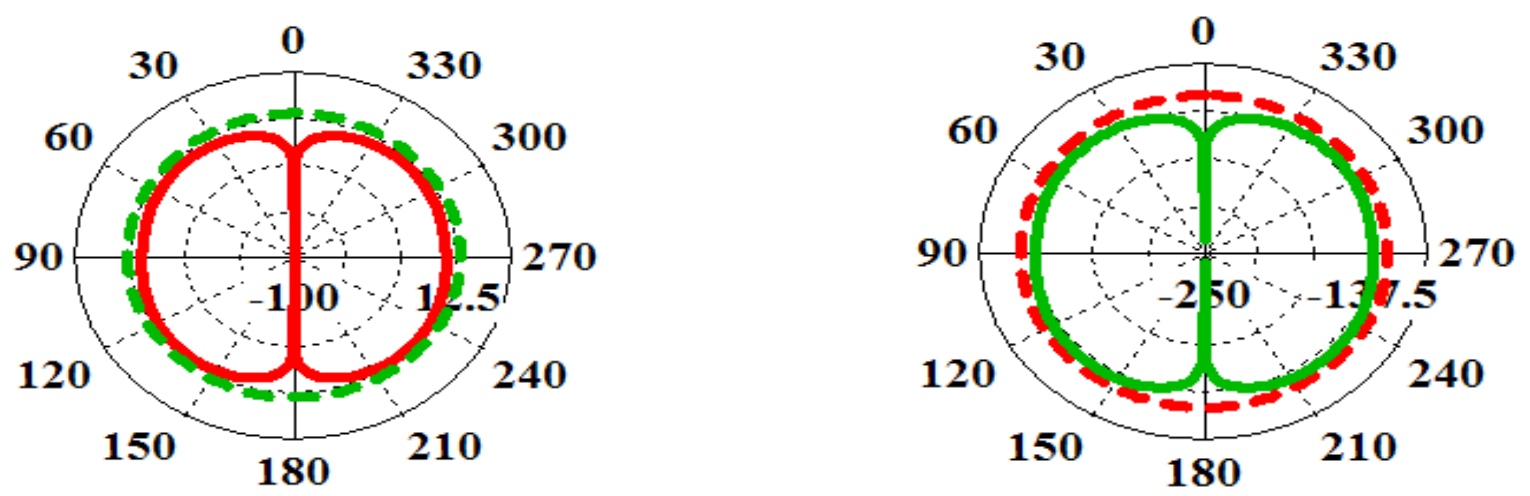

(b)
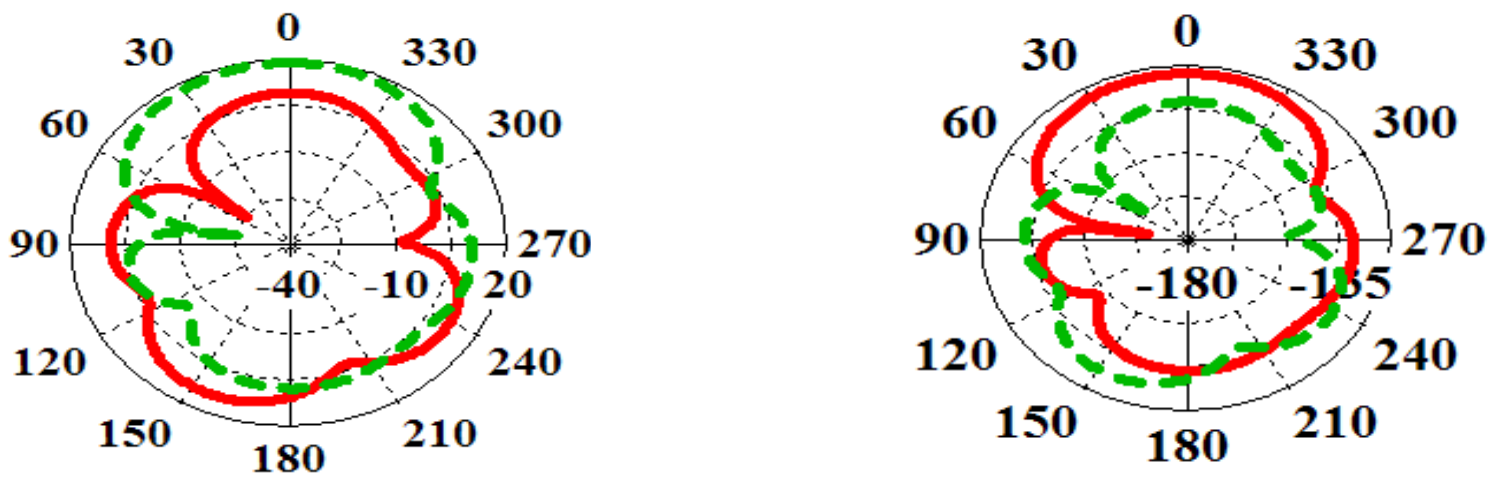

(c)

Figure 10. Radiation patterns of of multiple T-slots antenna at (a) $3.7 \mathrm{GHz}$ (b) $5.8 \mathrm{GHz}$ (c) $10.25 \mathrm{GHz}$. 


\section{Conclusion}

The compact multiple T-slot monopole antennas for UWB applications are proposed here. By inserting four different T-slot structures, the radiator can produced a tri-band performance and using the similar geometry another two T-slots are cut left and right sides of middle of the patch can produce the same tri-band frequency with improvement in return loss. The proposed structure is simulated using a CST MW studio produces a better return loss in the entire UWB region. The proposed system has compactness in size, have better impedance bandwidths 1000 $\mathrm{MHz}, 1000 \mathrm{MHz}$ and $2000 \mathrm{MHz}$ and a stable radiation patterns in the three resonate frequencies.

\section{References}

1. Li W,Zhai N, Chen R, Yu W. Non-foster impedance wideband matching technique for electrically small active antenna. International Journal of Antennas and Propagation. 2013. p.1-7. https://doi.org/10.1155/2013/531419

2. Osman MAR, Rahim MKA, Samsuri NA, Elbasheer MK, Ali ME. Textile UWB antenna bending and wet performance. International Journal of Antennas and Propagation; 2012. p.1-12. https://doi.org/10.1155/2012/251682

3. Ren W, Deng JY, Chen KS. Compact PCB monopole antenna for UWB applications. Journal of Electromagnetic Waves and Applications. 2007; 21(10):1411-20. https://doi. org/10.1163/156939307783239401

4. Gopikrishna M, Krishna DD, Chandran AR, Aanandan CK. Square monopole antenna for ultra wide band communication applications. Journal of Electromagnetic Waves and Applications. 2007; 21(11):1525-37. https://doi. org/10.1163/156939307782000299

5. Liu L, Xiong JP, Yin YZ, Zhao YL. A novel dual-164 Lim, Nagalingam and Tan F-shaped planar monopole antenna for ultrawide band communications. Journal of Electromagnetic Waves and Applications. 2008; 22(8-9):1106-14. https://doi. org/10.1163/156939308784158724
6. Schantz H. Dispersion and UWB antennas. International Workshop on Ultra Wideband System. Joint with Conference on Ultra Wideband System and Technologies; 2004. p. 161-5.

7. Liang JX, Choo CC, Dong CX, Parini CG. Study of a printed circular disc monopole antenna for UWB systems. IEEE Transactions on Antennas and Propagation. 2005; 53(11):3500-4. https://doi.org/10.1109/TAP.2005. 858598

8. Kasi B, Ping LC, Chakrabarty CK. A compact microstrip antenna for ultra wideband applications. European Journal of Science Research. 2011; 67(1):45-52.

9. Ain Q, Chattoraj N. A compact novel tapered U slot ultra wideband antenna. International Journal of Applied Science and Engineering. 2013; 3:301-15.

10. Aboufoul T, Parini C, Chen X, Alomainy A. Patternreconfigurable planar circular ultra-wideband monopole antenna. IEEE Transactions on Antennas and Propagation. 2013; 61(10):4973-80. https://doi.org/10.1109/TAP.2013. 2274262

11. Adnan S, Abd-Alhameed RA, See CH, Hraga HI, Elfergani ITE, Zhou D. A compact UWB antenna design for breast cancer detection. PIERS Online. 2010; 6(20):129-32. https://doi.org/10.2529/PIERS09102905533412. Lotfi P, Azarmanesh M, Soltani S. Rotatable dual band-notched UWB/triple-band WLAN reconfigurable antenna. IEEE Antennas and Wireless Propagation Letters. 2013; 12:104-7. https://doi.org/10.1109/LAWP.2013.2242842

13. Narayan P, Girish AK, Ray KP. Wide-band planar monopole antennas. IEEE Transactions on Antennas Propagation. 1998; 46(2):294-5. https://doi.org/10.1109/ 8.660976

14. Ammann MJ, Chen ZN. Wideband monopole antennas for multi-band wireless systems. IEEE Antennas and Propagation Magazine. 2003; 45(2):146-50. https://doi.org/10.1109/MAP. 2003.1203133

15. Chahat N, Zhadobow M, Sauleau R, Ito K. A compact UWB antenna for on-body applications. IEEE Transactions on Antennas and Propagation. 2011; 59(4):1123-31. https://doi.org/10.1109/TAP.2011.2109361 